\title{
钙华在第四纪研究中的应用: 以青藏高原为例
}

\author{
汪智军", 殷建军, 袁道先 \\ 中国地质科学院岩溶地质研究所, 国土资源部/广西壮族自治区岩溶动力学重点实验室, 桂林 541004 \\ * 联系人, E-mail: zhijunwang@karst.ac.cn
}

2017-12-11 收稿, 2018-01-25 修回, 2018-01-26 接受, 2018-03-21 网络版发表

中国地质科学院基本科研业务费专项(2017029)、广西自然科学基金(2017GXNSFFA198006, 2015GXNSFBA139206)和广西院士顾问项目资助

\begin{abstract}
摘要钙华广泛分布于陆地环境中, 且能够提供绝对的沉积年代(如铀系测年)和记录沉积时的地质与环境信息, 被广泛应用于第四纪研究中.目前我国大多数古钻华还缺乏系统的研究，尤其是对不同成因类型钙华的地质与环 境意义的认识还不够深入且存在争议。故本文以青藏高原上的钻华为例，综述了钻华在第四纪研究中的应用，探 讨了钙华研究中需要注意的问题, 并展望了未来的研究重点. 实例分析显示钻华在重建第四纪古气候环境变化中 有很大潜力. 其中, 青藏高原上热成因钙华的形成和演化, 除了受高原强烈的构造活动控制外, 还与印度夏季风 变化具有密切联系, 故有可能为青藏高原提供更多和覆盖更长时间尺度的古气候环境记录。此外, 钙华在区域地 表过程和地貌演化、构造和地热活动历史以及地质考古等领域也具有很大的研究价值. 基于钙华沉积的特点, 如 分布不连续、沉积形态和岩相结构多样、沉积机理复杂等, 提出了需要综合利用沉积学、岩相学、地球化学和年 代学等多种手段对钻华进行系统的研究.
\end{abstract}

关键词钙华，古气候环境，地貌演化，构造活动，地质考古，青藏高原

钻华, 又称石灰华, 是一种主要由碳酸钙矿物 (方解石、文石)组成的沉积物, 广泛分布于陆地环境 中 $^{[1 \sim 3]}$. 由于能够提供绝对的沉积年代 ${ }^{[4,5]}$ 和记录沉积 时的气候环境信息(详见文献[6,7]), 钲华被用来作为 一种重建第四纪气候环境演化的重要档案. 一般地, 钙华的沉积速率较快, 且对地表气候环境变化敏感, 故可以记录高分辨率(可达年、季尺度)的气候环境变 化信息 ${ }^{[8 \sim 10]}$, 从而有揭露短时间尺度和极端气候环境 事件的潜力. 许多研究表明钙华在过去土地覆被变 化 $^{[11]}$ 、区域地貌演化 ${ }^{[12,13]}$ 、构造和地热活动 ${ }^{[14 ~ 16] 以 ~}$ 及地质考古 ${ }^{[17 ~ 19]}$ 等研究中也具有很大应用价值.

过去30多年来, 国内外科学家们已经对钻华的 分类、形态和成因等进行了大量研究, 并对钙华的气 候环境意义进行了有益探索 ${ }^{[20,21]}$. 但是, 目前对不同 类型钙华的成因与意义的认识还不够深人且存在争
议. 通常地, 钙华沉积于开放的地表环境下, 其沉积 过程受到多种因素影响, 故如何准确地利用钙华进 行古气候环境重建仍有待大量深人的研究. 在我国, 包括广西、贵州、云南、四川和西藏等地分布着许多 钻华 ${ }^{[3]}$, 但大多数还缺乏系统的研究. 因此, 本文以 青藏高原为例, 综述国内外现有研究成果和认识, 对 钲华在第四纪气候环境变化、地貌演变、构造活动和 地质考古等研究中的应用以及研究中需要注意的问题 进行深人分析, 并指出今后钙华研究应该侧重的方向.

\section{1 铻华的成因、分类和分布}

\section{1 钻华成因}

在《钙华探秘》一书中, 刘再华等人 ${ }^{[21]}$ 将钙华的 成因总结为陆地上富含 $\mathrm{Ca}^{2+}$ 和 $\mathrm{HCO}_{3}^{-}$的水(如泉水、地

引用格式: 汪智军, 殷建军, 袁道先. 钙华在第四纪研究中的应用: 以青藏高原为例. 科学通报, 2018, 63: 1012-1023

Wang Z J, Yin J J, Yuan D X. Possibilities and problems associated with travertines and tufas in Quaternary studies: A case of the Tibetan Plateau (in Chinese). Chin Sci Bull, 2018, 63: 1012-1023, doi: 10.1360/N972017-01210 
表溪流、湖水等)因水中 $\mathrm{CO}_{2}$ 的消耗(主要是 $\mathrm{CO}_{2}$ 从水 中逸出或水中光合作用消耗 $\left.\mathrm{CO}_{2}\right)$, 或水的蒸发, 而 导致水溶液发生碳酸钙过饱和而发生沉淀. 通常地, 钙华的形成受到了气候、地质地貌、沉积水体地球化 学、水动力条件和生物等多种因素影响. 其中, 地形 决定的水动力条件改变 (即水流变化导致水中 $\mathrm{CO}_{2}$ 脱 气) 是钙华发生物理化学沉积的主控因子之一, Dreybrodt等人 ${ }^{[22]}$ 将其归结为固液界面间存在的扩散边界 层效应, 而Zhang等人 ${ }^{[23]}$ 认为是快速水流变化造成的 通气、射流和低压等物理效应. 除受物理化学过程控 制外, 钙华沉积也广泛受到生物作用的影响. 例如, $\mathrm{Liu}$ 等人 ${ }^{[24]}$ 研究发现某些水生植物能够通过光合作用 吸收 $\mathrm{CO}_{2}$ 而促使碳酸钻沉积. 一些苔藓、藻类和细菌 能为方解石和文石晶体生长提供垫面和成核位置, 或是促进晶体的捕捉和黏附等 ${ }^{[25]}$.

\section{2 钻华分类}

钙华的分类方法很多, 根据沉积水体和沉积模 式不同, Pedley ${ }^{[26]}$ 将钙华分为泉水钙华、河流障钙华、 湖泊钙华和沼泽钙华等几种. 根据沉积水体中 $\mathrm{CO}_{2}$ 来 源不同, Pentecost ${ }^{[1]}$ 将钙华分为大气成因(英文一般用 tufa表示)和热成因钙华(travertine)两大类：前者起因 于大气和土壤 $\mathrm{CO}_{2}$ 脱气作用, 通常具有较低的 $\delta^{13} \mathrm{C}$, 为 $-12 \% o \sim 2 \%$; 而后者主要起因于来自深部地幔或变 质成因 $\mathrm{CO}_{2}$ 脱气, 其 $\delta^{13} \mathrm{C}$ 较高, 为-1\%o 10\%o. Ford和 Pedley ${ }^{[2]}$ 描述了这两大类钙华的基本特征, 其中大气 成因钙华的沉积速率较低、孔隙度高, 通常含有丰富 的大型、微型植物和无脊椎动物残体; 而热成因钙华 通常具有较高的沉积速率, 常形成较好的层状结构, 其岩相结构以物理化学和微生物成因结晶为主, 通常 缺乏原地的大型植物和动物残骸. 然而, 在地热泉水 沉积系统的远端低洼地带, 随着泉水温度降低或是与 地表雨水混合后, 也有大型水生植物的生长, 故也形 成与大气成因钙华相似的结构 ${ }^{[27]}$. 由于沉积热成因钙 华的泉水并非都是热水, 刘再华等人 ${ }^{[21]}$ 也将大气成因 类和热成因类钙华分别称之为表生钻华和内生钙华.

\section{3 钻华分布}

钻华在现今多种不同气候条件下都有发现, 但 主要分布在有大量降水和年均温度较高的石灰岩地 $区^{[1 \sim 3]}$. 在一些干旱地区, 如埃及西部沙漠地区 ${ }^{[18]}$ 和 埃塞俄比亚高原 ${ }^{[28]}$, 也分布有更新世湿润气候阶段
沉积的钲华. 热成因钙华主要分布在构造活动强烈 的地区 (如意大利中部和土耳其西部的伸展构造活动 带 ${ }^{[29]}$ )或火山活动区 (如美国黄石 ${ }^{[30]}$ ). Pentecost和 $\mathrm{Zhang}^{[3]}$ 基于当时报道过的 88 个钙华点地理分布发 现, 我国大气成因钙华主要出现在温暖湿润的南方 地区, 如广西、贵州、四川和云南等地, 而在寒冷和 干旱的北方地区较少; 热成因钙华主要出现在构造 活动强烈的地区, 如青藏高原、滇西和川西等地.

青藏高原上分布着大量钙华，包括热成因钙华、 大气成因钙华和湖成钙华等, 其中热成因钙华分布最 为广泛. 青藏高原地处喜马拉雅大型地热带, 出露了 许多地热泉, 多达600 700处 ${ }^{[31]}$. 这些地热泉主要沿 晚新生代形成的几条大型南-北向裂谷(如亚东-谷露裂 谷)系统、喀喇昆仑走滑断裂以及班公-怒江缝合带和 雅鲁藏布江缝合带内的断裂分布(图1). 地热水循环概 念模型显示, 地表冷水沿断裂系统渗透进人地下做深 部循环, 吸收了大量来自地幔岩浆或熔融层的热能, 最后在热力对流下被运移至地表出露 ${ }^{[32]}$. 高原上热成 因钙华主要形成于流经碳酸盐岩地层的地热水, 如在 拉萨地块和特提斯喜马拉雅地区, 这两个地区广泛分 布着奥陶纪至始新世的石灰岩. 沿深部断裂循环的地 下水携载了大量来自地幔岩浆或岩石变质脱碳作用 产生的 $\mathrm{CO}_{2}$, 在高温高压条件下强烈地溶解周围碳酸 盐岩, 致使地热水大量富集 $\mathrm{Ca}^{2+}$ 和 $\mathrm{HCO}_{3}^{-}, \mathrm{HCO}_{3}^{-}$浓度 高达 10 20 mmol/ $/ \mathrm{L}^{[31]}$. 由于水中的 $\mathrm{CO}_{2}$ 分压远远高 于空气, 故地热水在地表出露后很容易发生 $\mathrm{CO}_{2}$ 脱 气, 使得水中碳酸钙高度过饱和而生成大量钙华.

迄今为止, 对青藏高原上的钙华有过详细研究 的仅有为数不多的几个点, 主要是热成因钙华, 包括

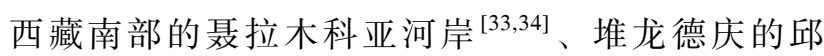
桑 ${ }^{[35,36]}$ 、藏西南的扎达布日 ${ }^{[37]}$ 、藏北的荣玛 ${ }^{[38,39]}$ 和青 藏公路沿线钙华 ${ }^{[40]}$ 以及西藏中部的几个盐湖周边的 钲华 (如扎布耶盐湖钙华 ${ }^{[41]}$ 、多格错仁盐湖 ${ }^{[42]}$ 、当雄 错盐湖 ${ }^{[43]}$ ). 高原上的大气成因钙华分布不多, 仅有 极少数报道 ${ }^{[44]}$. 此外, 青藏高原上分布了许多内陆 湖泊, 其中很多古湖岸上沉积有湖泊成因钙华, 如昂 拉仁错西岸 ${ }^{[45 ~ 47]}$ 和当雄错南岸 ${ }^{[43]}$.

\section{2 钻华在第四纪研究中的应用}

\section{1 钻华定年}

同洞穴石笋和珊瑚等碳酸盐沉积物一样, 钙华 

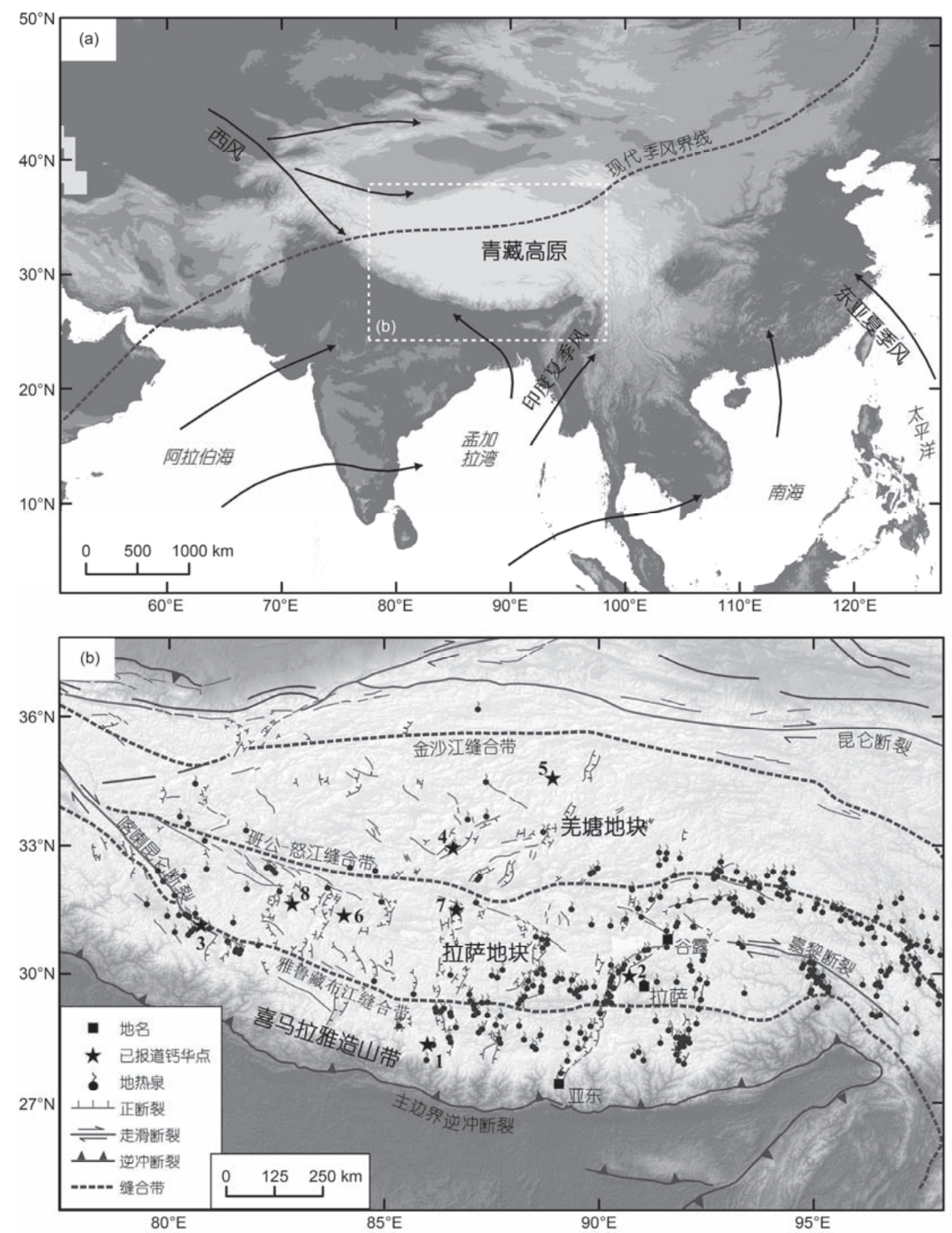

图 1 亚洲季风影响区域(a)与青藏高原地热泉分布及其构造背景(b). 1, 科亚河; 2, 邱桑; 3, 扎达布日; 4, 荣玛; 5, 多格错仁盐湖; 6, 扎布耶盐 湖; 7, 当雄错盐湖; 8, 昂拉仁错

Figure 1 Maps showing regions affected by the Asian Monsoon (a) and distribution of geothermal springs on the Tibetan Plateau as well as their tectonic setting (b). 1, Keya River; 2, Chusang; 3, Tirthapuri; 4, Rongma; 5, Dogai Coring Salt Lake; 6, Zabuye Salt Lake; 7, Tangqungco Salt Lake; 8, Nganglaring Tso

能够通过铀系不平衡测年技术获得绝对的年龄 ${ }^{[4,5]}$. 其中, 铀-钍(U-Th)测年法可以覆盖晚第四纪的大部
分时段，测年上限可达距今 60 多万年 ${ }^{[48]}$, 而铀-铅 $(\mathrm{U}-\mathrm{Pb})$ 法可以对第三纪钲华进行定年 ${ }^{[49]}$. 另外, 一些 
研究也利用钙华本身或内含的有机物质进行 ${ }^{14} \mathrm{C}$ 测 年 ${ }^{[50]}$, 或利用混人钙华里的碎屑石英或长石颗粒进 行光释光 (optically stimulated luminescence, OSL)测 年 ${ }^{[51]}$. 其他方法, 如 ${ }^{228} \mathrm{Ra}^{226} \mathrm{Ra}^{[52]}$ 、热释光(thermoluminescence, TL) 和电子自旋共振 (electron spin resonance, ESR $)^{[53]}$ 以及氨基酸外消旋化分析 (amino acid racemization, AAR $)^{[54]}$ 等也被用于钻华定年.

需要注意的是, 受古老碳酸盐岩中溶解的“死 碳” 影响, 钲华等碳酸盐沉积物 ${ }^{14} \mathrm{C}$ 测年存在很大问 题, 需要进行校正 ${ }^{[4]}$. 对于热成因钻华来说, 其沉积 前老碳酸盐岩的溶解主要受深部 $\mathrm{CO}_{2}$ 驱动, 故沉积中 含 ${ }^{14} \mathrm{C}$ 较少, 不宜用 ${ }^{14} \mathrm{C}$ 法进行测年. 由于钙华沉积于 地表, 会受到碎屑 ${ }^{230} \mathrm{Th}$ 污染和早期成岩蚀变作用(导 致 $\mathrm{U}$ 和 Th损失或增加) 影响 ${ }^{[4]}$. 因此, 在钙华U-Th定 年工作中, 需要仔细选择合适的定年材料(如原生和

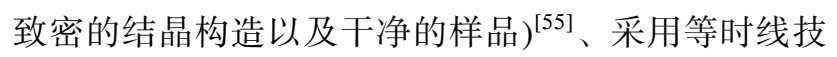
术矫正碎屑污染或者与其他测年方法对比等.

\section{2 古气候环境变化档案}

钙华在古气候环境变化研究中的一个重要优势 在于可以提供高分辨率的气候环境变化信息. 通常地, 钙华沉积速率较快, 每年可达数毫米到 $1 \sim 2 \mathrm{~cm}^{[10]}$. 较 快的沉积速率使得钙华常形成较好的纹层结构, 可 以反映周期性的气候环境变化. 许多近期连续沉积 的钙华研究案例显示层状钻华稳定碳氧同位素和微 量元素变化可以指示季节性的温度和降水变化 ${ }^{[6,8,10]}$. 一些对干旱或半干旱地区的钙华研究显示, 钙华主 要形成于温暖湿润的气候阶段, 如更新世的间冰期 或间冰阶阶段 ${ }^{[18,28,29]}$. 这些研究结果表明, 在较长时 间尺度上, 钲华与气候之间具有密切关系, 表现为: 暖湿气候条件能够带来较好的植被和土壤 $\mathrm{CO}_{2}$ 产生, 并提供大量降水补给地下水, 从而更有利于钙华的 形成. 而古钙华 $\delta^{18} \mathrm{O}, \delta^{13} \mathrm{C}$ 和微量元素变化也能够指 示年代际至百年、甚至千年至轨道时间尺度上的古温 度和降水变化 ${ }^{[6,56]}$.

青藏高原上有详细研究报道的主要是热成因钙 华. 沈永平 ${ }^{[34]}$ 最早对西藏南部科亚河左岸阶地上的 古热成因钙华进行了 ${ }^{14} \mathrm{C}$ 测年研究, 显示钙华形成于 22 18 ka BP, 当时为一个干凉的气候环境. 王绍 令 ${ }^{[40]}$ 利用 ${ }^{14} \mathrm{C}$ 法对藏北青藏公路沿线几个古钙华点的 ${ }^{14} \mathrm{C}$ 定年, 也显示钙华沉积主要发生在22 15 ka BP. 但是, 受 “死碳” 影响, 这些钙华年龄可能比真实值偏
老. Zentmyer等人 ${ }^{[33]}$ 利用U-Th法对科亚钙华进行了重 新定年, 结果显示钲华沉积于11.6 5.4 ka BP, 属于早中全新世, 这一时段对应于印度夏季风降雨增强.

$\mathrm{GaO}$ 等人 ${ }^{[38]}$ 研究了藏北荣玛地区的钙华, 铀系定 年数据也显示钙华主要沉积于印度夏季风较强的早一 中全新世 $(11.5 \sim 4.6 \mathrm{ka} \mathrm{BP})$. 覃建勋等人 ${ }^{[39]}$ 对荣玛一 个钙华锥体进行定年和地球化学研究发现, 钙华锥 成 “半球面式生长”, 其纵剖面能够记录连续的气候 变化信息. 他们根据钻华 $\delta^{18} \mathrm{O}, \mathrm{Sr} / \mathrm{Ca}$ 和 $\mathrm{Sr} / \mathrm{Ba}$ 与温度 和降雨的关系, 初步揭示了荣玛地区未次冰消期以 来的古气候变化.

最近, Wang等人 ${ }^{[36]}$ 对拉萨附近的邱桑古钻华进 行了初步研究, U-Th测年数据显示钻华主要沉积于 几个不同时期, 从下至上分别为 486 ka BP(MIS 13a), 212 ka BP(MIS 7c), 128 ka BP(MIS 5e)和12 7 ka BP(早全新世), 这些沉积时段也较好地对应于印 度夏季风较强的阶段. Wang等人 ${ }^{[37]}$ 对阿里象泉河上 游河流阶地上发育的钙华台 U-Th定年也显示，钙华 沉积主要发生在印度夏季风较强的时期, 如末次冰 消期早期(MIS 5e) 和全新世早期.

此外, 青藏高原上一些封闭湖泊古湖岸上发育 的钙华也被用于研究第四纪古湖面变迁和气候环境 变化. 雷国良等人 ${ }^{[45]}$ 研究了西藏西部昂拉仁错古湖 岸阶地上发育的钙华, 发现这类钙华是湖泊演化过 程中不同时期形成的自生碳酸盐沉积物. Hudson等 人 ${ }^{[46]}$ 对昂拉仁错钙华进行了 ${ }^{14} \mathrm{C}$ 和U-Th定年, 重建了

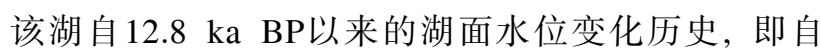
$12.8 \sim 2.3 \mathrm{ka} \mathrm{BP}$, 湖泊水位均高于现代湖面高度 $(4727$ $\mathrm{m})$, 且最高湖面出现在10.3 8.6 ka BP时, 比现代湖 面高了近 $135 \mathrm{~m}$; 同高原上其他湖泊一样，这时期高 湖面的出现主要与北半球太阳辐射增加驱动的印度 夏季风增强有关. 此外, Hudson和Quade ${ }^{[47]}$ 基于青藏 高原上包括昂拉仁错在内的几个高位古湖岸线钙华 定年, 发现在最暖湿的早全新世高原古湖面面积扩 张呈现出很大东西差异, 其中西部湖面扩张了约4倍, 而东部地区仅为 2 倍左右，由此也证明高原气候乃至 季风具有明显的区域分异特征.

青藏高原，平均海拔>4000 m, 被称为“世界屋 脊”, 是全球气候变化最敏感的地区之一. 目前, 高 原气候主要为寒冷、半干旱到干旱的气候类型, 且受 印度夏季风影响显著(图1). 对于大多数地区, 尤其 是高原南部地区, 印度夏季风带来的降水约占全年 
降水量的 $70 \%$ 以上 ${ }^{[57]}$. 水是钻华形成之母, 故对于半 干旱-干旱区的青藏高原来说, 钙华发育演化有可能 记录了许多季风降水变化的信息.

\section{3 在区域地貌演化中的应用}

钙华能够提供绝对年代, 且与气候环境具有密 切关系, 使其成为研究地表过程和地貌演化的一个 重要工具. 较快的沉积和固结成岩使得钙华常常在 不同的陆地环境(如坡地、河流和湖泊等)中相对保存 较好, 故而在揭露区域地表过程和地貌长期演化历 史方面具有很大潜力. 一些河流系统, 如匈牙利多瑙 河 $^{[12]}$ 、西班牙Tagus 河 ${ }^{[58]}$ 、意大利 Valdelsa河谷 ${ }^{[13]}$ 中 的钙华研究都发现, 钙华保存在不同的河流阶地表 面, 能够用来揭示千年和轨道时间尺度上的河流侵 蚀和地貌演化历史.

Zentmyer等人 ${ }^{[33]}$ 根据藏南科亚河左岸阶地上覆 盖的钙华U-Th定年(11.6 ka BP)和阶地高度 $(18 \mathrm{~m})$, 计算了全新世以来科亚河下切速率为 $1.6 \mathrm{~mm} / \mathrm{a}$. 他们 还发现钙华与河流砾石层有混合胶结, 由此指示钙 华沉积与河流侵蚀作用大致是同步的, 且都跟印度 夏季风降雨的增强有关. 同样地, Wang等人 ${ }^{[37]}$ 根据 西藏西部阿里象泉河上游扎达布日钙华与河流砾石 层的混合或互层特征, 推断河流阶地上的钙华台与 河流下切和阶地的形成大致同步, 也都主要是发生 在印度夏季风较强的时期, 如三级阶地形成于末次 间冰期早期(ca. $128 \mathrm{ka} \mathrm{BP}$ ), 二级阶地形成于全新世 早期(10 8.8 ka BP). 他们计算得到了象泉河在末次 间冰期以来和全新世的下切速率分别为 $2 \sim 3$ 和 $~ 4.2$ $\mathrm{mm} / \mathrm{a}$, 由此也揭示出季风较强阶段的河流侵蚀速率 比平均侵蚀速率较高.

Wang等人 ${ }^{[36]}$ 和Meyer等人 ${ }^{[35]}$ 对拉萨附近的邱桑 钙华点的研究发现, 钙华与源自周围陡坡上的坡积 物(主要表现为泥石流相)互层, 形成了较厚的钻华坡积层沉积序列. 钙华U-Th和坡积层 ${ }^{14} \mathrm{C}$ 定年数据表 明, 周围斜坡上的侵蚀和坡脚堆积过程也都主要是 发生在印度夏季风较强的时期, 如全新世早期. 另 外, 对坡积层沉积物的狍粉分析表明, 邱桑地点在全 新世早期的植被类型为高山草甸, 以蒿草和禾本科 植物为主 ${ }^{[35]}$.

其他研究也表明, 在现今寒冷、半干旱-干旱的 青藏高原上, 许多洪积、冲积和坡积等地表过程和地 貌的形成都主要是受温暖和潮湿的气候条件(如强季
风(降雨)驱动的 ${ }^{[59,60]}$. 因此, 在这些地表环境下沉积 的钙华将会为高原古气候环境变化以及气候驱动的 地表过程和地貌演化研究提供重要手段.

\section{4 揭示区域构造和地热活动历史}

由于地球深部断裂直接诱发或控制了地下热水 的补给、循环和上升, 所以热成因钙华的形成与断裂 和地震活动也具有密切关系, 其沉积地点可以用来 识别活动的或有潜在危险的断裂、地震带. Hancock 等人 ${ }^{[14]}$ 基于土耳其、希腊爱琴海地区、意大利北部 亚平宁山脉和美国盆山地区晚第四纪热成因钙华实 地考察, 发现钙华可以揭示许多新构造的特征及其 活动历史, 并由此提出了钻华构造学 (travitonics)的 概念. 许多研究发现裂隙-山脊型热成因钲华定年为 地质学家们提供了许多盆地张性断裂的构造活动特 征及运动学方面的信息 ${ }^{[15,16]}$. 此外, 一些热成因钙华 被用来估算深部地热流体库的温度及其持久供热能 力 $^{[61]}$. 地热水在地表沉积钙华的同时也伴随着大量 的 $\mathrm{CO}_{2}$ 排放进人大气, 而钙华沉积时段和沉积规模的 研究将有助于了解深部 $\mathrm{CO}_{2}$ 释放历史 ${ }^{[62]}$.

目前, 青藏高原上利用热成因钻华研究断裂构 造活动历史的研究还尚未见诸报道. 彭贵和焦文 强 ${ }^{[63]}$ 对青藏高原东南缘滇西剑川盆地龙门邑钙华(发 育有一条大型钙华脊)的研究发现，晚更新世以来剑 川断裂经历过了多次构造活动变化, 且这些构造活 动可能代表了剑川地区的古地震事件. 一些研究也 报道了青藏高原上的多个盐湖, 如扎布耶盐湖 ${ }^{[41]}$ 、多 格错仁盐湖 ${ }^{[42]}$ 和当雄错盐湖 ${ }^{[43]}$ 等周围发现了很多热 成因钙华的发育, 且这些钙华中富集 $\mathrm{K}, \mathrm{Li}, \mathrm{Cs}$ 和B等 元素, 故可以用来重建古地热流体的地球化学和年 代学特征, 进而揭示盐湖成矿过程和历史.

\section{5 在地质考古中的应用}

泉水地点在过去常常吸引着古人类前往寻找水 源, 且温泉能够为寒冷气候条件下古人类们提供取暖 条件来抵御严寒. 因此, 钙华中或附近经常有考古遗 存或其他人类活动痕迹的发现 ${ }^{[18,19]}$. 例如, 在墨西哥 东南部Cuatrociénegas盆地里的钙华表面发现了很多 古人类脚印, 钲华U-Th定年显示在10.55 7.24 ka BP 美洲先民在此活动 ${ }^{[19]}$.

同样地, 在西藏拉萨附近的邱桑钙华地点, 离现 代温泉不远的钙华表面发现了许多人类手印和脚印, 
Zhang 等人 ${ }^{[17]}$ 研究发现这些手印和脚印是古人类在 早先沉积的钙华软泥上留下的印痕. 他们通过对古 人类手印和脚印下的钻华OSL定年, 显示早在22 20 $\mathrm{ka} \mathrm{BP}$ 的末次冰盛期就已经有古人类在此活动了. 然 而, 由于钙华沉积地层和释光剂量率模拟的复杂性, 该年龄可能存在问题. Meyer等人 ${ }^{[35]}$ 通过对该钙华点 系统的沉积地层分析, 并利用改进的U-Th定年, 结 合 OSL 和 ${ }^{14} \mathrm{C}$ 定年, 对钙华表面的古人类手印和脚印 的形成时代进行了更加精确的限定, 重新确定了这 些古人类手印和脚印的年龄最低限约为 $7.4 \mathrm{ka} \mathrm{BP}$, 最高限为 $12.7 \sim 8.2 \mathrm{ka} \mathrm{BP}$. 他们对相关考古数据和古 人类迁徙路途时间花费模拟分析表明, 古人类在农 耕文明前的早全新世时期就已经在青藏高原内部进 行常年活动和永久定居了, 当时高原受印度夏季风 加强影响而处于一个气候适宜期.

高海拔、缺氧、气候寒冷和干旱等条件使得青藏 高原成为地球上人类生存和居住最极端的环境之一. 野外调查发现高原上大多数考古文物(如石器)或人 类活动遗迹主要来自于靠近淡水源地的场所, 如泉 水地点、湖岸线或河流阶地上 ${ }^{[64,65]}$. 因此, 对钙华、 湖岸线和河流阶地的定年将会为这些考古发现提供 直接的年代或者地层年代框架, 从而为研究史前人 类向青藏高原迁徙和定居的时间提供更多证据.

\section{3 钙华研究中需要注意的几个问题讨论}

\section{1 热成因钻华的气候环境意义}

同洞穴石笋相似, 大气成因钙华能够保存丰富 的气候环境信息, 而热成因钙华能否记录地上的气 候信号受到了很多争议. 传统上认为热成因钙华的 形成主要与构造活动控制的水热活动有关, 如构造 活动减弱, 地下深部的温度和压力下降, 会使得地热 泉水头差变小, 泉水流量减小, 出露范围缩小, 最终 导致钙华沉积减少或停止 ${ }^{[66]}$. 另外, 地震活动也能 够造成地下含水层裂隙网络结构改变, 进而导致温 泉出露或消亡, 也会使得钲华沉积发生变迁 ${ }^{[67]}$. 然 而, 许多意大利、土耳其的热成因钙华研究表明, 除 受构造活动控制外, 热成因钙华 (尤其是较大规模和 范围)的发育演化还与气候有关, 即钙华沉积主要是 发生在温暖湿润的气候阶段 ${ }^{[29]}$. 诸多青藏高原上热 成因钙华定年研究实例也表明钙华主要形成于印度 夏季风降水增强的时期(见前述).
青藏高原自晚新生代以来发生了强烈的构造活 动, 发育了许多深大断裂(如裂谷)系统, 控制了高原 内部的热水活动. 基于地热泉水氢氧同位素的研究 表明, 青藏高原地热泉主要受大气降水和冰川/冰雪 融水补给, 且大多数热泉水在地下深部循环快速, 其 循环时间仅为 20 40 $\mathrm{a}^{[66,68]}$. 然而, 佟伟等人 ${ }^{[31]}$ 所著 《西藏温泉志》中报道了目前高原上大多数温泉已经 处于萎缩或消亡阶段, 而高原上古钙华(还有其他类 型的泉华, 如硅华和盐华)的规模和分布范围是相当 大的. 因此, 可以推断高原上大规模的钲华沉积和较 大的钙华沉积体的形成可能与温暖湿润的气候(即印 度夏季风增强)有密切关系, 广泛分布的热成因钙华 至少在年代际-百年时间尺度以上能够记录古(季风) 气候的演化.

另一个问题是, 如何提取热成因钙华中来自地 上的气候环境信息. 袁道先等人 ${ }^{[69]}$ 利用多成因分析 法探讨了滇西北香格里拉下给温泉中 $\mathrm{CO}_{2}$ 来源, 根据 平面几何重心图计算了各成因 $\mathrm{CO}_{2}$ 所占比例, 结果为 土壤 $\mathrm{CO}_{2}$ 占 $17.39 \%$, 深部幔源 $\mathrm{CO}_{2}$ 占 $36.23 \%$, 变质成 因 $\mathrm{CO}_{2}$ 占 $46.37 \%$. 其他温泉气体 $\mathrm{CO}_{2}, \mathrm{~N}_{2}, \mathrm{H}_{2} \mathrm{~S}, \mathrm{CH}_{4}$ 和 惰性气体(如 $\mathrm{He}$ )等的组成比例及其同位素也可以用 来示踪温泉水的来源 ${ }^{[70]}$. 此外, 许多研究也显示大 多数青藏高原上出露地表的地热水都是来自深部地 热流体与浅部冷水的混合, 通过热储温度 (如 $\mathrm{SiO}_{2}$ 温 标法和阳离子温标法)和冷热水混合比例(硅-焓模型 法)估算，显示浅层冷水的混合比例高达 50\% 80\%, 浅层热储循环深度为600 900 $\mathrm{m}^{[66,68]}$. 这些评估分析 方法对探讨热成因钻华的气候环境指示意义具有很 大帮助. 此外, 很多热成因钙华是中低温地热泉水流 出地表一段距离后沉积的, 其在沉积过程中受地表 气温或降水变化影响显著, 故而能记录气候环境信 息. 例如, Sun和Liu ${ }^{[71]}$ 对云南白水台热成因钙华研究 表明, 泉口附近的钙华 $\delta^{18} \mathrm{O}$ 在很大程度上能反映地 表温度的变化, 而下游钙华 $\delta^{18} \mathrm{O}$ 能指示降水变化.

诚然, 与大气成因钙华相比，热成因钲华稳定同 位素解释较为复杂, 其中钙华 $\delta^{18} \mathrm{O}$ 可能受到深部水岩作用影响, 而 $\delta^{13} \mathrm{C}$ 主要反映了深部 $\mathrm{CO}_{2}$ 源的同位素 特征. 研究表明青藏高原上不同时期沉积的热成因 䥻华具有不同的地球化学特征, 如 $\delta^{18} \mathrm{O}$ 变化幅度可 高达6\%o 10\%o(文献[39]和笔者未发表数据). 如此高 的 $\delta^{18} \mathrm{O}$ 变化幅度, 可能与深部水-岩氧同位素交换作 用、沉积过程中的同位素不平衡分馏或沉积后的蚀变 
作用等有关. 然而, 西藏天门洞石笋 $\delta^{18} \mathrm{O}$ 也显示出

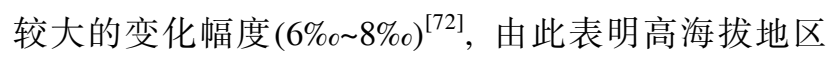
的大气降水 $\delta^{18} \mathrm{O}$ 对气候变化更加敏感, 可能受到降 水量、水汽源和温度变化的综合影响. 青藏高原上钙 华 $\delta^{18} \mathrm{O}$ 的特征及其影响因素, 以及其如何记录气候 环境变化, 还有待大量的数据来揭示.

\section{2 钻华指标解译}

由于钙华沉积于开放的地表环境下, 其沉积机 制较为复杂, 准确提取记录在这些沉积物中的古气 候环境变化信息时会遇到困难. 受快速的 $\mathrm{CO}_{2}$ 脱气和 碳酸钙沉积速率影响, 很多钙华在沉积过程中常存 在很大的同位素不平衡分馏 ${ }^{[73]}$. 此外, 不同地点和 不同钙华沉积体系, 如坡地、渠道、跌水处和水池 等, 受不同的水体物理化学性质、地表气温和降水变 化、地形决定的 $\mathrm{CO}_{2}$ 脱气作用、水流条件和生物活动 等影响, 钙华沉积速率、 $\delta^{18} \mathrm{O}$ 和 $\delta^{13} \mathrm{C}$ 的气候环境指代 意义也存在很大差异 ${ }^{[7]}$. 最新的研究发现钙华沉积速 率的季节性变化会放大(对于表生钙华)或抹平(对于 内生钙华)基于钙华氧同位素重建的古温度季节变化 幅度 ${ }^{[74,75]}$. 因此, 如刘再华 ${ }^{[7]}$ 所建议, 有必要开展现 代钙华沉积机理试验观测研究. 如有可能, 需要对所 调查地点不同沉积环境下的现代钙华沉积机理及其 控制因素进行系统研究, 对钙华沉积速率、稳定碳氧 同位素等与气候(温度和降水)的关系进行试验观测 验证.

\section{3 钻华沉积形态和岩相结构多样}

受不同的沉积环境和沉积过程控制, 钙华通常 具有各种不同的沉积形态和结晶构造. 过去的研究 已经识别出各种不同的钙华晶体类型和形态, 包括 物理化学成因晶体(如树枝状晶体)或微生物成因晶 体(如凝块状微晶)组成的壳层结构以及包壳粒、内碎 屑或外来颗粒等粒状结构等(详见文献[76]). 详细的 岩相学特征解译表明不同的钙华微岩相结构及其形 态组合能指示特定的钲华沉积过程(包括物理化学或 生物作用过程)和沉积环境(如泉口近端钙华雉/丘, 斜坡地和远端的平地或洼地).

另外, 钲华通常具有较高的初始孔隙度, 使得钙 华沉积以后会受到地表水或地下水渗透的影响而发 生早期成岩蚀变作用(early digenesis), 包括钙华自身 溶解、重结晶、亮晶泥晶化、胶结、有机物氧化和其
他自生矿物的形成等 ${ }^{[20]}$. 早期成岩作用能够使得原 生晶体结构与蚀变晶体结构(包括胶结物)变得难以 区分, 增加了钙华微岩相结构解译的复杂性. 同时, 成岩蚀变作用也会在一定程度上改变钙华地球化学 特征(如 $\delta^{18} \mathrm{O}$ 和 $\left.\delta^{13} \mathrm{C}\right)^{[6]}$.

因此, 有必要对古钙华进行系统的沉积形态学 和微岩相学分析, 识别不同种类的沉积相, 并依据组 成这些沉积相的微岩相结构及其组合的形成条件, 来指示特定的钙华沉积环境和沉积过程, 最后根据 相似环境条件下现代钙华沉积的试验观测结论, 更 准确地进行钙华古气候环境重建. 详细的岩相学分 析也有助于评估钙华早期成岩蚀变作用及其影响.

\section{4 钻华沉积分布不连续}

在许多情况下, 古钙华沉积具有分布不连续的 特征, 其常常由多个泉口的水流沉积而成, 形成复杂 的钙华沉积综合体, 且常受泉口时空变迁影响. 另 外, 许多不同地貌环境(如冰缘坡地、河流、湖泊和 沼泽等)下形成的钙华常与各种陆源碎屑物混合或互

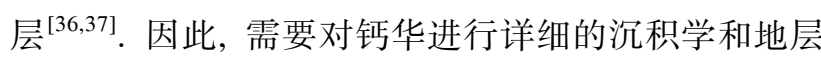
学研究, 利用野外地貌成图、沉积剖面观察等手段, 并结合钲华和其他沉积物定年, 对钙华堆积模式和 沉积阶段进行模拟分析, 从而更好地运用钙华进行 古气候环境变化、地质地貌演化以及地质考古研究.

\section{4 展望}

通过青藏高原钻华研究案例介绍可知, 钙华因 其能够进行绝对定年和提供沉积时的环境信息, 在 第四纪古气候环境变化、区域地貌演化、构造和地热 活动以及地质考古中都有巨大的应用潜力. 但是, 目 前钙华在第四纪研究中的应用还较少, 尤其是钙华 对古气候环境变化的指示意义, 如钙华发育演化与 古气候环境的关系、钙华气候环境代用指标(如 $\delta^{18} \mathrm{O}$ 和 $\delta^{13} \mathrm{C}$ ) 解译, 以及钻华沉积岩相学特征等的深人认 识还有待通过大量的研究来揭示. 我国钙华分布广 泛，其中蕴藏的丰富的地质、地貌、气候和环境信息 亟待探索. 青藏高原地处地中海-喜马拉雅大型地热 带内, 对高原上热成因钙华发育演化及其地质与环 境意义研究将会深化对该地热带内地热资源的形成、 特征及开发利用的认识，也有助于利用钙华研究“一 路一带”沿线地区的地质地貌演变和气候环境变化. 展望未来, 我们认为钙华研究可以在以下几个方面 


\section{取得突破：}

(1) 过去季风气候变化. 我国广大地区气候受季 风(包括东亚夏季风和印度夏季风)降水影响显著. 钻 华因沉积速率快会形成较好纹层结构, 如云南白水 台钙华 ${ }^{[10]}$, 其研究在揭示高分辨率(可达年、季尺度) 的季风降水变化方面有很大潜力, 有利于揭露持续 时间短的极端气候事件. 青藏高原上广泛分布的钙 华, 凭借其铀系测年优势, 有可能提供更多和覆盖较 长时间的晚第四纪古印度夏季风演化记录. 通过更 多和更大范围的钻华研究, 将有助于回答诸如季风

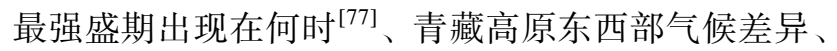
东亚夏季风与印度夏季风变化的联系和差异等问 题 ${ }^{[47]}$.

（2）区域地表过程和地貌演化. 根据与其他陆源 堆积的地层关系分析, 钙华可以为地表过程和地貌 演化提供年代框架, 同时也为地表过程和地貌演化 中的气候环境制约提供佐证. 除热成因钙华外, 高原 古湖岸线上的湖成钙华能够重建湖岸地貌的发育演
化和湖泊变迁 ${ }^{[46]}$, 值得进行深入研究. 我国南方地区 几处古老洞穴, 如广西桂林罗田大岩和上林大龙洞口 发现有较厚的古钙华沉积, 如果能够突破年代问题, 将为岩溶地貌的发育和演化研究提供重要手段.

(3) 区域断裂和地热活动. 我国青藏高原和滇西 地区分布有许多大型的裂脊型钙华 ${ }^{[63,68,69]}$, 其发育与 断裂或地震活动具有密切联系, 故可以用于厘定断 裂或地震活动的发生时间，揭示更多地热活动特征 及其演化.

（4）地质考古. 在寒冷干旱的青藏高原上，泉点 常常吸引着史前人类前往, 所以这些泉水沉积物中 或附近可能会有更多的考古发现，其研究将为西藏 古人类迁徙和定居的时间和模式提供更多重要证据.

基于钙华沉积的特点，包括分布不连续、沉积形 态和岩相结构多样、沉积过程复杂等, 需要建立一套 完整的钲华研究方法. 我们建议综合利用沉积学、岩 相学、地球化学和年代学等多种手段, 对所调查钙华 地点进行系统的研究.

\section{参考文献}

1 Pentecost A. The quaternary travertine deposits of Europe and Asia Minor. Quat Sci Rev, 1995, 14: 1005-1028

2 Ford T D, Pedley H M. A review of tufa and travertine deposits of the world. Earth-Sci Rev, 1996, 41: 117-175

3 Pentecost A, Zhang Z. A review of Chinese travertines. Cave Karst Sci, 2001, 28: 15-28

4 Garnett E R, Gilmour M A, Rowe P J, et al. ${ }^{230} \mathrm{Th} /{ }^{234} \mathrm{U}$ dating of Holocene tufas: Possibilities and problems. Quat Sci Rev, 2004, 23: 947-958

5 Sierralta M, Sandor K, Melcher F, et al. Uranium-series dating of travertine from Sutto: Implications for reconstruction of environmental change in Hungary. Quat Int, 2010, 222: 178-193

6 Andrews J E. Palaeoclimatic records from stable isotopes in riverine tufas: Synthesis and review. Earth-Sci Rev, 2006, 75: 85-104

7 Liu Z H. Research progress in paleoclimatic interpretations of tufa and travertine (in Chinese). Chin Sci Bull, 2014, 59: 2229-2239 [刘再 华. 表生和内生钙华的气候环境指代意义研究进展. 科学通报, 2014, 59: 2229-2239]

8 Matsuoka J, Kano A, Oba T, et al. Seasonal variation of stable isotopic compositions recorded in a laminated tufa, SW Japan. Earth Planet Sci Lett, 2001, 192: 31-44

9 Andrews J E, Brasier A T. Seasonal records of climatic change in annually laminated tufas: Short review and future prospects. J Quat Sci, 2005, 20: 411-421

10 Liu Z H, Sun H L, Lu B Y, et al. Wet-dry seasonal variations of hydrochemistry and carbonate precipitation rates in a travertine-depositing canal at Baishuitai, Yunnan, SW China: Implications for the formation of biannual laminae in travertine and for climatic reconstruction. Chem Geol, 2010, 273: 258-266

11 Liu Z H, Sun H L, Li H C, et al. $\delta^{13} \mathrm{C}, \delta^{18} \mathrm{O}$ and deposition rate of tufa in Xiangshui River, SW China: Implications for land-cover change caused by climate and human impact during the late Holocene. Geol Soc Lond Spec Publ, 2011, 352: 85-96

12 Ruszkiczay-Rudiger Z, Fodor L, Bada G, et al. Quantification of Quaternary vertical movements in the central Pannonian Basin: A review of chronologic data along the Danube River, Hungary. Tectonophysics, 2005, 410: 157-172

13 Capezzuoli E, Gandin A, Sandrelli F. Calcareous tufa as indicators of climatic variability: A case from the Southern Tuscany (Italy). In: Pedley M, Rogerson M, eds. Tufas, Speleothems and Stromatolites: Unravelling the Physical and Microbial Controls. London: The Geological Society, 2010. 263-281 
14 Hancock P L, Chalmers R M L, Altunel E, et al. Travitonics: Using travertines in active fault studies. J Struct Geol, 1999, 21: $903-916$

15 Brogi A, Capezzuoli E. Travertine deposition and faulting: The fault-related travertine fissure-ridge at Terme S. Giovanni, Rapolano Terme (Italy). Int J Earth Sci, 2009, 98: 931-947

16 Mesci B L, Gursoy H, Tatar O. The evolution of travertine masses in the Sivas area (Central Turkey) and their relationships to active tectonics. Turk J Earth Sci, 2008, 17: 219-240

17 Zhang D D, Li S H. Optical dating of Tibetan human hand- and footprints: An implication for the palaeoenvironment of the last glaciation of the Tibetan Plateau. Geophys Res Lett, 2002, 29: 16-1-16-3

18 Smith J R, Giegengack R, Schwarcz H P, et al. A reconstruction of quaternary pluvial environments and human occupations using stratigraphy and geochronology of fossil-spring tufas, Kharga Oasis, Egypt. Geoarchaeology, 2004, 19: 407-439

19 Felstead N J, Gonzalez S, Huddart D, et al. Holocene-aged human footprints from the Cuatrocienegas Basin, NE Mexico. J Archaeol Sci, 2014, 42: 250-259

20 Pentecost A. Travertine. Berlin: Springer, 2005

21 Liu Z H, Sun H L, Yan H, et al. Tufa/Travertine Investigation (in Chinese). Beijing: Science Press, 2016 [刘再华, 孙海龙，晏浩，等. 钙华探秘. 北京: 科学出版社, 2016]

22 Dreybrodt W, Buhmann D, Michaelis J, et al. Geochemically controlled calcite precipitation by $\mathrm{CO}_{2}$ outgassing: Field measurements of precipitation rates in comparison to theoretical predictions. Chem Geol, 1992, 97: 285-294

23 Zhang D D, Zhang Y J, Zhu A, et al. Physical mechanisms of river waterfall tufa (travertine) formation. J Sediment Res, 2001, 71: 205-216

24 Liu Z H, Li Q, Sun H L, et al. Diurnal variations of hydrochemistry in a travertine-depositing stream at Baishuitai, Yunnan, SW China. Aquat Geochem, 2006, 12: 103-121

25 Riding R. Microbial carbonates: The geological record of calcified bacterial-algal mats and biofilms. Sedimentology, 2000, 47: 179-214

26 Pedley H M. Classification and environmental models of cool freshwater tufas. Sediment Geol, 1990, 68: 143-154

27 Capezzuoli E, Gandin A, Pedley M. Decoding tufa and travertine (fresh water carbonates) in the sedimentary record: The state of the art. Sedimentology, 2014, 61: 1-21

28 Moeyersons J, Nyssen J, Poesen J, et al. Age and backfill/overfill stratigraphy of two tufa dams, Tigray Highlands, Ethiopia: Evidence for Late Pleistocene and Holocene wet conditions. Paleogeogr Paleoclimatol Paleoecol, 2006, 230: 165-181

29 De Filippis L, Faccenna C, Billi A, et al. Plateau versus fissure ridge travertines from Quaternary geothermal springs of Italy and Turkey: Interactions and feedbacks between fluid discharge, paleoclimate, and tectonics. Earth-Sci Rev, 2013, 123: 35-52

30 Fouke B W. Hot-spring systems geobiology: Abiotic and biotic influences on travertine formation at Mammoth Hot Springs, Yellowstone National Park, USA. Sedimentology, 2011, 58: 170-219

31 Tong W, Liao Z J, Liu S B, et al. Thermal Springs in Tibet (in Chinese). Beijing: Science Press, 2000 [佟伟, 廖志杰, 刘时涁, 等. 西 藏温泉志. 北京: 科学出版社, 2000]

32 Tan H B, Zhang Y F, Zhang W J, et al. Understanding the circulation of geothermal waters in the Tibetan Plateau using oxygen and hydrogen stable isotopes. Appl Geochem, 2014, 51: 23-32

33 Zentmyer R, Myrow P M, Newell D L. Travertine deposits from along the South Tibetan Fault System near Nyalam, Tibet. Geol Mag, 2008, 145: 753-765

34 Shen Y P. Discovery of ancient tufas in Keya, Tibet and its significance (in Chinese). Chin Sci Bull, 1986, 31: 1654-1657 [沈永平. 西 藏科亚古泉华的发现及其意义. 科学通报, 1986, 31: 1654-1657]

35 Meyer M C, Aldenderfer M S, Wang Z, et al. Permanent human occupation of the central Tibetan Plateau in the early Holocene. Science, 2017, 355: 64-67

36 Wang Z, Meyer M C, Hoffmann D L. Sedimentology, petrography and early diagenesis of a travertine-colluvium succession from Chusang (southern Tibet). Sediment Geol, 2016, 342: 218-236

37 Wang Z, Meyer M C, Gliganic L A, et al. Timing of fluvial terrace formation and concomitant travertine deposition in the upper Sutlej River (Tirthapuri, southwestern Tibet) and paleoclimatic implications. Quat Sci Rev, 2017, 169: 357-377

38 Gao J, Zhou X, Fang B, et al. U-series dating of the travertine depositing near the Rongma hot springs in northern Tibet, China, and its paleoclimatic implication. Quat Int, 2013, 298: 98-106

39 Qin J X, Han P, Che X C, et al. Resuming the Holocene paleoclimatic using $\delta^{18} \mathrm{O}$ and trace element of travertine in Rongma area, Tibet (in Chinese). Earth Sci Front, 2014, 21: 312-322 [覃建勋, 韩鹏, 车晓超, 等. 利用荣玛地区温泉钲华 $\delta^{18} \mathrm{O}$ 及微量元素重建西藏全 新世以来古气候. 地学前缘, 2014, 21: 312-322]

40 Wang S L. Paleo-sinters and its significance, Qinghai-Xizang Plateau (in Chinese). Hydrogeol Eng Geol, 1992, 19: 29-31 [王绍令. 青藏 高原古泉华及其意义. 水文地质工程地质, 1992, 19: 29-31] 
41 Zhao Y Y, Cui Y B, Zhao X T. Geological and geochemical features and significance of travertine in travertine-island from Zhabuye salt lake, Tibet, China (in Chinese). Geol Bull Chin, 2010, 29: 124-141 [赵元艺, 崔玉斌, 赵希涛. 西藏扎布耶盐湖钙华岛钙华的地质地 球化学特征及意义. 地质通报, 2010, 29: 124-141]

42 Niu X S, Liu X F, Chen W X. Travertine in South bank of Dogai Coring, Tibet: Geochemical characteristics and potash geological significance (in Chinese). Acta Sedimentol Sin, 2013, 31: 1031-1040 [牛新生, 刘喜方, 陈文西. 西藏多格错仁南岸钙华地球化学特征 与钾盐地质意义. 沉积学报, 2013, 31: 1031-1040]

43 Niu X S, Zheng M P, Liu X F, et al. Sedimentary property and the geological significance of travertines in Qinghai-Tibetan Plateau (in Chinese). Sci Tech Rev, 2017, 35: 59-64 [牛新生, 郑绵平, 刘喜方, 等. 青藏高原钙华沉积属性特征及其地质意义. 科技导报, 2017, 35: 59-64] Sweeting M M, Bao H S, Zhang D. The problem of palaeokarst in Tibet. Geograph J, 1991, 157: 316-325

Lei G L, Zhang H C, Li Z Z, et al. Geochemical features and significance of shorline tufa from a closed-basin lake Ngangla Ring Tso in the western Tibetan Plateau (in Chinese). Quat Sci, 2013, 33: 839-847 [雷国良，张虎才，李志忠，等. 青藏高原西部昂拉仁错古湖岸 钲华沉积的地球化学特征及环境意义. 第四纪研究, 2013, 33: 839-847]

Hudson A M, Quade J, Huth T E, et al. Lake level reconstruction for 12.8-2.3 ka of the Ngangla Ring Tso closed-basin lake system, southwest Tibetan Plateau. Quat Res, 2015, 83: 66-79

Hudson A M, Quade J. Long-term east-west asymmetry in monsoon rainfall on the Tibetan Plateau. Geology, 2013, 41: 351-354

Cheng H, Edwards R L, Sinha A, et al. The Asian monsoon over the past 640000 years and ice age terminations. Nature, 2016, 534: 640-646

49 Quade J, Rasbury E T, Huntington K W, et al. Isotopic characterization of late Neogene travertine deposits at Barrancas Blancas in the eastern Atacama Desert, Chile. Chem Geol, 2017, 466: 41-56

50 Pazdur A, Pazdur M F, Szulc J. Radiocarbon dating of Holocene calcareous tufa in southern Poland. Radiocarbon, 1988, 30: 133-152

51 Rich J, Stokes S, Wood W, et al. Optical dating of tufa via in situ aeolian sand grains: A case example from the Southern High Plains, USA. Quat Sci Rev, 2003, 22: 1145-1152

52 Eikenberg J, Vezzu G, Zumsteg I, et al. Precise two chronometer dating of Pleistocene travertine: The ${ }^{230} \mathrm{Th} /{ }^{234} \mathrm{U}$ and ${ }^{226} \mathrm{Ra} \mathrm{ax} /{ }^{226} \mathrm{Ra}(0)$ approach. Quat Sci Rev, 2001, 20: 1935-1953

53 Engin B, Guven O, Koksal F. Thermoluminescence and electron spin resonance properties of some travertines from Turkey. Appl Radiat Isot, 1999, 51: 729-746

54 Torres T, Ortiz J E, Morena M A G, et al. Ostracode-based aminostratigraphy and aminochronology of a tufa system in central Spain. Quat Int, 2005, 135: 21-33

55 Mallick R, Frank N. A new technique for precise uranium-series dating of travertine micro-samples. Geochim Cosmochim Acta, 2002, 66: $4261-4272$

56 Doran T L, Herries A I R, Hopley P J, et al. Assessing the paleoenvironmental potential of Pliocene to Holocene tufa deposits along the Ghaap Plateau escarpment (South Africa) using stable isotopes. Quat Res, 2015, 84: 133-143

57 Bookhagen B, Burbank D W. Toward a complete Himalayan hydrological budget: Spatiotemporal distribution of snowmelt and rainfall and their impact on river discharge. J Geophys Res Earth Surf, 2010, 115: F03019

58 Ortiz J E, Torres T, Delgado A, et al. A review of the Tagus river tufa deposits (central Spain): Age and palaeoenvironmental record. Quat Sci Rev, 2009, 28: 947-963

59 Bookhagen B, Thiede R C, Strecker M R. Abnormal monsoon years and their control on erosion and sediment flux in the high, and northwest Himalaya. Earth Planet Sci Lett, 2005, 231: 131-146

60 Schlutz F, Lehmkuhl F. Holocene climatic change and the nomadic Anthropocene in Eastern Tibet: Palynological and geomorphological results from the Nianbaoyeze Mountains. Quat Sci Rev, 2009, 28: 1449-1471

61 Pasvanoğlu S, Chandrasekharam D. Hydrogeochemical and isotopic study of thermal and mineralized waters from the Nevşehir (Kozakli) area, Central Turkey. J Volcanol Geoth Res, 2011, 202: 241-250

62 D'Alessandro W, Giammanco S, Bellomo S, et al. Geochemistry and mineralogy of travertine deposits of the SW flank of Mt. Etna (Italy): Relationships with past volcanic and degassing activity. J Volcanol Geoth Res, 2007, 165: 64-70

63 Peng G, Jiao W Q. Time of deposition of the calcium sinter in Jianchuan, Yunnan and the new activities of the Jianchuan fault (in Chinese). J Seismol Res, 1990, 13: 166-172 [彭贵, 焦文强. 剑川钙泉华的沉积时代及剑川断裂的新活动. 地震研究, 1990, 13: $166-172]$

64 Huang W W. The prehistoric human occupation of the Qinghai-Xizang Plateau. Götinger Geogr Abhand, 1994, 95: 201-219

65 Yuan B, Huang W, Zhang D. New evidence for human occupation of the northern Tibetan Plateau, China during the Late Pleistocene. Chin Sci Bull, 2007, 52: 2675-2679 
66 Fang B, Yang Y J, Wang G H, et al. Characteristics and resources evaluation of the Jiwa geothermal field in central Qiangtang, northern Tibet, China (in Chinese). Geol Bull China, 2009, 28: 1335-1341 [方斌, 杨运军, 王根厚, 等. 藏北芫塘中部吉瓦地热田的特征及其 资源评价. 地质通报, 2009, 28: 1335-1341]

67 Xiao Q, Shen L C, Yuan D X, et al. Response of the Beiwenquan hot spring's hydrochemical features in Chongqing to the Wenchuan earthquake of magnitude 8.0 in Sichuan (in Chinese). Carsol Sin, 2009, 28: 385-390 [肖琼, 沈立成, 袁道先, 等. 重庆北温泉水化学 特征对汶川 8.0 级地震的响应. 中国岩溶, 2009, 28: 385-390]

68 Zhou L. Characteristics of the typical hot springs in the central Tibet (in Chinese). Master Dissertation. Beijing: China University of Geosciences, 2012 [周立. 西藏中部典型温泉特征. 硕士学位论文. 北京：中国地质大学, 2012]

69 Yuan D X, Liu Z H, Lin Y S, et al. Karst Dynamic Systems of China (in Chinese). Beijing: Geological Publishing House, 1996 [袁道先, 刘再华, 林玉石, 等. 中国岩溶动力系统. 北京: 地质出版社, 1996]

70 Dai J, Dai C, Song Y. Geochemical characters, carbon and helium isotopic compositions of natural gas from hot springs of some areas in China. Sci China Ser B, 1994, 24: 758-768

71 Sun $\mathrm{H} \mathrm{L}$, Liu Z H. Wet-dry seasonal and spatial variations in the $\delta^{13} \mathrm{C}$ and $\delta^{18} \mathrm{O}$ values of the modern endogenic travertine at Baishuitai, Yunnan, SW China and their paleoclimatic and paleoenvironmental implications. Geochim Cosmochim Acta, 2010, 74: 1016-1029

72 Cai Y, Cheng H, An Z, et al. Large variations of oxygen isotopes in precipitation over south-central Tibet during Marine Isotope Stage 5. Geology, 2010, 38: 243-246

73 Kele S, Demeny A, Siklosy Z, et al. Chemical and stable isotope composition of recent hot-water travertines and associated thermal waters, from Egerszalok, Hungary: Depositional facies and non-equilibrium fractionation. Sediment Geol, 2008, 211: 53-72

74 Sun H L, Liu Z H, Yan H. Oxygen isotope fractionation in travertine-depositing pools at Baishuitai, Yunnan, SW China: Effects of deposition rates. Geochim Cosmochim Acta, 2014, 133: 340-350

75 Yan $\mathrm{H}$, Liu Z H, Sun H L. Effect of in-stream physicochemical processes on the seasonal variations in $\delta^{13} \mathrm{C}$ and $\delta^{18} \mathrm{O}$ values in laminated travertine deposits in a mountain stream channel. Geochim Cosmochim Acta, 2017, 202: 179-189

76 Gandin A, Capezzuoli E. Travertine: Distinctive depositional fabrics of carbonates from thermal spring systems. Sedimentology, 2014, 61: $264-290$

77 Chen J H, Rao Z G, Liu J B, et al. On the timing of the East Asian summer monsoon maximum during the Holocene-Does the speleothem oxygen isotope record reflect monsoon rainfall variability? Sci China Earth Sci, 2016, 59: 2328-2338 


\title{
Possibilities and problems associated with travertines and tufas in Quaternary studies: A case of the Tibetan Plateau
}

\author{
Zhijun Wang ${ }^{*}$, Jianjun Yin \& Daoxian Yuan \\ Key Laboratory of Karst Dynamics, Ministry of Land and Resources \& Guangxi, Institute of Karst Geology, Chinese Academy of Geological Sciences, \\ Guilin 541004, China \\ * Corresponding author, E-mail: zhijunwang@karst.ac.cn
}

Travertines and tufas, precipitated from waters (hydrothermal and ambient temperature karstic waters respectively) enriched in calcium and bicarbonate ions, are widespread in continental settings. Both carbonate deposits are important archives for Quaternary studies, as they can be absolutely dated (e.g. via uranium-series dating) and provide evidence of climatic and environmental conditions at the time of formation. Yet, most of the travertines and tufas in China still lack investigation and little is known about the nature of geological and paleoenvironmental information stored in these deposits. Here we summarize previous studies of travertines and tufas from the Tibetan Plateau, with an emphasis on possibilities and problems associated with these carbonates in Quaternary studies, and lastly provide our perspectives on the future of travertine and tufa research. Travertines are quite common on the Tibetan Plateau and preferentially occur along active tectonic zones, such as the approximately north-south trending rift systems and some strike-slip faults caused by the uplift of the Plateau and subsequent east-west extensional deformation of the Tibetan crust during the Late Cenozoic. At present these travertines are under-researched, but several previous studies have shown that the travertine deposition on the Plateau is not only controlled by tectonics but also closely associated with the intensity of the Indian summer monsoon. Some lacustrine tufas deposited on the paleoshorelines of several closed-basin lakes on the Plateau are able to reconstruct lake-level (and hence paleomonsoon) change. It is therefore expected that the widely-distributed travertines and tufas on the Tibetan Plateau have great potential to provide insight into past monsoonal climate change. Furthermore, travertines and tufas preserved in different terrestrial settings, such as periglacial slope, fluvial, and lacustrine environments on the Plateau, appear to be a promising tool for unravelling climate-driven surface processes and geomorphological change of an area. The formation of travertines (e.g. travertine fissure-ridge) is often linked with active tectonics and can thus provide more evidence of faulting and geothermal activities on the Plateau. In several instances, archeological finds (e.g. ancient human hand- and footprints) are stratigraphically or spatially associated with travertines or tufas; thus the dating of these carbonates may provide the timing of human migration and settlement of the Tibetan Plateau, and allow us to better understand the prevailing climatic and environmental conditions during site occupation and abandonment. Several problems might be encountered in the study of the travertines and tufas. Firstly, the travertines and tufas tend to accumulate discontinuously due to the tempo-spatial shift in spring orifice location and water flow pattern, and may be mixed with terrigenous sediments. Another problem is that a variety of travertine and tufa lithofacies and fabrics within these deposits are observed, and thus a detailed petrographic analysis is needed. In addition, these carbonate deposits are prone to early diagenetic alteration as they commonly have relatively high initial porosity and permeability, resulting in modification of the original geochemical composition, and hence, the paleoclimatic proxy signals recorded in these deposits. Thus, careful analysis must be conducted in order to distinguish primary fabrics from altered material. Last but not least, the processes responsible for travertine and tufa precipitation are extremely complex, and often lead to difficulties in the interpretation of climatic and environmental signals stored in these deposits. Further research should focus on determining the relationships between travertine and tufa proxies (e.g. oxygen and carbon stable isotopes) and climate (temperature, precipitation) based on field measurements and experiments carried out in different depositional environments, such as proximal vents, intermediate slopes, or distal flats and depressions. Considering the problems mentioned above, we suggest that a multidisciplinary approach, including geomorphological, sedimentological, petrographic, geochronological and geochemical investigations, is necessary in the study of travertines and tufas.

travertines and tufas, paleoclimate and paleoenvironment, landscape evolution, tectonic activities, geoarcheology, the Tibetan Plateau

doi: 10.1360/N972017-01210 